\title{
СОТРУДНИЧЕСТВО В ГИДРОЭНЕРГЕТИЧЕСКОЙ СФЕРЕ КАК КЛЮЧЕВОЙ АСПЕКТ ИНДИЙСКОЙ ПОМОЩИ РАЗВИТИЮ БУТАНА
}

\author{
(C) 2019 Мельникова Анна Александровна \\ студент \\ Московский государственный институт международных отношений (университет) \\ Министерства иностранных дел Российской Федерации, Россия, Москва \\ E-mail: anna.melnikova18@gmail.com \\ (c) 2019 Мельникова Елена Викторовна \\ кандидат экономических наук, доцент, заведующий кафедрой экономики \\ и организации отраслей химико-лесного комплекса \\ Сибирский государственный университет науки и технологий \\ имени академика М.Ф. Решетнева, Россия, Красноярск \\ E-mail: melena6921@mail.ru
}

Статья посвящена вопросам экономического сотрудничества Индии и Бутана в гидроэнергетической сфере. Рассмотрены особенности и проблемы двустороннего сотрудничества, механизм и нормативно-правовая база предоставления индийской помощи развитию гидроэнергетической инфраструктуры Бутана. Выявлены основные препятствия для укрепления сотрудничества между двумя странами в указанной сфере, а также предложены основные пути их устранения.

Ключевые слова: индийско-бутанские отношения, экономическое сотрудничество, гидроэнергетика, трансграничные поставки электроэнергии, энергетические проекты

В условиях глобализации трансграничные энергетические проекты, балансирующие спрос и предложение энергетических ресурсов двух или нескольких стран - явление закономерное, обладающее возрастающим общеполитическим значением. Отмечая социальную и экологическую значимость, технологическую сложность производства электроэнергии [1, с. 29], многие авторы указывают на уникальность роли электроэнергетики в экономическом развитии многих стран.

Факторами расширения трансграничного электроэнергетического сотрудничества являются: специфичность электроэнергии как товара, в т.ч. сложность запасания, необходимость оперативного балансирования мощностей и объемов потребления электроэнергии. Среди примеров успешного взаимодействия в энергетической сфере - общий рынок электроэнергии в скандинавских странах Nord Pool, ЕЭС/ОЭС в Восточной Европе, консорциум USTE - в Западной Европе и т.п. Еще одним аргументом в пользу политизации энергетического фактора является его рассмотрение с позиций «мягкой силы» в двусторонних отношениях.

Взаимодействие Бутана и Индии по линии развития гидроэнергетического потенциала горной страны на протяжении долгого времени являлось образцовым примером взаимовыгодного сотрудничества в Южной Азии. Горное королевство располагает внушительным ресурсами в данной сфере: по международным оценкам общая мощность водотоков Бутана составляет 30000 МВт. Суммарная мощность рентабельного производства гидроэнергии составляет 23760 МВт. [2]. Для сравнения, суммарная мощность гидроэнергетики Непала равна 43000 МВт, а внутренний спрос составит 7000 МВт на ближайшие 25 лет» [3, с. 131], что, несомненно, свидетельствует об избытке энергетических мощностей и в соседней стране. Для строительства гидроэлектростанций на территории Бутана требуются значительные объемы капиталовложений, которые Нью-Дели предоставляет в обмен на дешевую электроэнергию, причем доля Бутана в объеме финансирования индийским правительством грантовых и кредитных программ по развитию стран Южно-Азиатского региона в 2016/17 и 2017/18 финансовых годах составила соответственно 85,2\% и 83,4\% (рассчитано авторами по [4, с. 42]).

В Индии же наблюдается «резкое противоречие между растущими потребностями в энергоресурсах и относительно ограниченной соб- 
ственной ресурсной базой» [5], причем попытки решить проблему путем реализации проекта «энергетического кольца» противоречат политическим интересам Нью-Дели в регионе [5]. В целом, сотрудничество Индии и Бутана реализуется в условиях экономического соперничества Индии и Китая в Южной Азии и конкуренции Бутана и Непала по объемам гидроэнергетического потенциала. Существует даже мнение, что «с помощью Индии Непал может превзойти своего соседа - Королевство Бутан в производстве энергии» [3, с. 131]. Тем не менее, сегодня львиная доля индийской помощи направляется в Бутан.

Правовой основой для отношений двух стран в указанной отрасли служат Договор о сотрудничестве в сфере гидроэнергии (2006 г.) и Протокол к нему (2009 г.). В рамках указанного соглашения Нью-Дели обязался помочь Тхимпху в увеличении мощностей горного королевства по производству гидроэлектроэнергии на 10000 МВт к 2020 г. [6]. Согласно договору, построенные ГЭС находятся в собственности Бутана, однако весь объем электроэнергии сверх минимума, необходимого для домашнего потребления, экспортируется в Индию. Таким образом, горное королевство поставляет своему южному соседу около 75\% всей производимой электроэнергии [7]. Тем не менее, Бутан не удовлетворён существующим уровнем использования гидроэнергетических ресурсов страны и надеется увеличить свои доходы от экспорта электроэнергии. По официальным данным, новейшая бутанская ГЭС Тала приносит до 7 млрд. рупий (более 100 млн. долларов) в бюджет горного королевства, однако этой суммы едва ли хватает на импорт ископаемого топлива в зимний период, когда выработка электроэнергии затруднена [8].

В настоящее время основу сотрудничества Индии и Бутана в гидроэнергетической сфере составляют три крупных проекта: Пунатсангчxy-I (1200 МВт), Пунатсангчху-II (1020 МВт) и Мангдечху (720 МВт) [9]. Таким образом, общая мощность указанных проектов 2940 МВт, что существенно ниже заданной планки в 10000 МВт. Условия финансирования строительства указанных проектов менее выгодны для бутанской стороны: теперь соотношение льготных кредитов и грантов составляет 60:40 для Пунатсангчху-I и 70:30 для проектов Пунатсангчху-II и Мангдечху [10]. Согласно официальной информации, проект Мангдечху завершен на 100\%, в то время как соответствующие показатели для Пунатсангч-
Xу-I и Пунатсангчху-II составили на конец 2018 г. 84,86\% и 79,22\% соответственно [6].

В 2014 г. также было подписано индийско-бутанское межправительственное соглашение о реализации ряда проектов суммарной мощностью 2120 МВт. Соотношение кредитного и льготного элементов финансовой помощи со стороны Нью-Дели составит 70:30 [6]. Существенным изменением по сравнению с гидроэнергетическими инициативами из предыдущего пакета стало то, что новые ГЭС будут принадлежать в равных долях индийским и бутанскими корпорациям, что также уменьшает выгоду Тхимпху от реализации проектов [8].

В настоящее время имеются определенные сложности с реализацией предложенных инициатив. Во-первых, реальная стоимость осуществления проектов существенно превосходит объемы изначально выделенного финансирования. К октябрю 2018 г. суммарные затраты на строительство всех трех ГЭС превысили 4,226 млрд. долларов по сравнению с изначальными 1,515 млрд. долларов. Затраты на реализацию инициатив выросли на 108\% в случае с Мангдечху и на $154 \%$ в случае с Пунатсангчху-II, в то время как стоимость проекта Пунатсангчху-I возросла на $267 \%$ [9]. Таким образом, стремительный рост затрат на строительство указанных гидроузлов вызывает вопросы относительно экономической рентабельности проектов.

Во-вторых, камнем преткновения в двусторонних отношениях в сфере гидроэнергии является вопрос цены электроэнергии, экспортируемой Бутаном в Индию. Так как электроэнергия является ключевым экспортным товаром королевства, Тхимпху стремится сбывать данный товар по максимальной возможной цене, что противоречит интересам Нью-Дели. Руководство горного королевства объясняет свою позицию тем, что Индия импортирует электроэнергию по сниженным тарифам. Сложности в переговорах о цене тормозят процесс ввода гидроузлов в эксплуатацию. Например, планировалось, что ГЭС Мангдечху начнет работать к концу 2018 г., однако трудные переговоры о согласовании тарифа на поставку электроэнергии удалось завершить лишь к апрелю 2019 г. [11].

В-третьих, ввиду изменения соотношения элементов гранта и кредита в финансовой помощи, выделяемой Нью-Дели, осуществление совместных гидроэнергетических проектов становится все менее выгодным для Бута- 
на. Как уже было отмечено, теперь $60-70 \%$ от общей стоимости реализации дорогостоящих гидроэнергетических проектов предоставляются Индией на условиях кредитов, что является тяжелым бременем для экономики горного королевства. В условиях резкого сокращения прибыли от экспорта электроэнергии после 2007 г. Бутан стремительными темпами приближается к долговому кризису [9]. По официальным данным, общий долг северного королевства перед Нью-Дели превысил 123 млрд. рупий (около 1,76 млрд. долларов), что составляет 77\% всего иностранного дола Бутана и 87\% его ВВП [12].

В-четвертых, недовольство Тхимпху вызывает также желание Нью-Дели изменить модель сотрудничества в сфере гидроэнергетики. Согласно новым правилам трансграничной торговли электроэнергией от 5 декабря 2016 г., правительство Индии предъявляет к зарубежным поставщикам электроэнергии следующее требование: импортером электроэнергии может выступать лишь компания, 50\% которой принадлежит индийской стороне. Таким образом, новые ГЭС должны находиться в совместной собственности Индии и Бутана, что ограничит возможность Тхимпху диктовать тариф на поставки электроэнергии [8].

B-пятых, Бутан в значительной степени зависит от ситуации на внутреннем рынке электроэнергии Индии. Если в случае острой нехватки электроэнергии, как это произошло в северной Индии в 2012 г. [13], горное королевство может за короткий период времени получить значительную прибыль, то избыток энергии на внутреннем рынке южноазиатского гиганта чреват для Бутана падением цен на электроэнергию [14]. Как следствие, Тхимпху может лишиться основного источника дохода. Горное королевство ощутило на собственном опыте опасность ориентации на Индию как на монопольного импортера бутанской гидроэлектроэнергии в 2017 г., когда перенасыщение внутреннего рынка электроэнергии южноазиатского гиганта вызвало сокращение доходов в гидроэнергетической отрасли Бутана [8].

Таким образом, упомянутые факторы омрачают сотрудничество Индии и Бутана в гидроэнергетической сфере. Как уже было отмечено, доходы горного королевства от внешней торговли в значительной степени зависят от экспорта электроэнергии в Индию. Как следствие, в условиях сокращения доходности сотрудничества в указанной сфере Тхимпху вынужден искать пути диверсификации источников бюджетных поступлений, в том числе посредством интенсификации сотрудничества с другими странами, например, с КНР.

Для недопущения изменения баланса индийско-китайских сил в Бутане Нью-Дели следует рассмотреть возможности гарантирования Тхимпху стабильного дохода от продажи электроэнергии. Этого можно достичь путем повышения закупочной цены на бутанскую гидроэнергию до среднеиндийского уровня или же привлечения других государств к сотрудничеству в энергетической сфере. Потенциальным потребителем электроэнергии из Бутана может стать Бангладеш, испытывающая значительный недостаток энергоресурсов.

Отметим, что Индия традиционно выступает главным политическим и экономическим партнером Бутана. Так же как и в случае Непала, Нью-Дели накладывает существенные ограничения на внешнюю политику Тхимпху. Таким же образом, торговля и транзит гималайского королевства зависят от Индии: на южноазиатского гиганта приходится более $85 \%$ всего торгового оборота Бутана. В настоящее время Китай ищет возможности для укрепления своих позиций на северной границе Индии, в том числе в Бутане.

На современном этапе все более отчётливо прослеживается несостоятельность индийского подхода к своим северным соседям, в том числе к Бутану. Очевидно, что индийское руководство обладает существенными рычагами влияния на Тхимпху, к которым можно отнести финансовую помощь, инвестиции, возможность экономической блокады. Невнимательность к интересам гималайского королевства лишь подталкивают местные политические элиты к интенсификации сотрудничества с внерегиональными акторами, такими как Китай. Для недопущения изменения баланса сил Индии и Китая в Бутане Нью-Дели следует обеспечить Тхимпху стабильный доход от экспорта электроэнергии. Возможными путями достижения указанной цели могут стать повышение закупочной цены на гидроэнергию и привлечение к сотрудничеству в указанной сфере третьих стран, например, Бангладеш. 


\section{Библиографический список}

1. В.Е. Байдин Международная торговля электроэнергией // Российский внешнеэкономический вестник. 2009. № 3 c. 29-33.

2. Гидроэнергетический профиль Королевства Бутан на сайте Международной ассоциации гидроэнергетики. Режим доступа: www.hydropower.org/country-profiles/bhutan (дата обращения: 22.05.2019).

3. Харина О.А. Конфликт интересов Индии и Китая в Непале // Южно-российский журнал социальных наук. 2016. № 1. URL: https://cyberleninka.ru/article/n/konflikt-interesov-indii-i-kitaya-v-nepale (дата обращения: 06.06.2019).

4. Емельянова Н. Н. «Мягкая сила» Индии в Южной Азии: стратегия на смену реактивности // Вестник Московского университета. Серия 12. Политические науки. 2017. № 4. URL: https://cyberleninka.ru/article/n/ myagkaya-sila-indii-v-yuzhnoy-azii-strategiya-na-smenu-reaktivnosti (дата обращения: 06.06.2019).

5. Кулешова Н.С. Современные тенденции энергетического сотрудничества в Южной Азии // Мировая политика.-2017.- № 1._С. 13-26. DOI: 10.7256/2409-8671.2017.1.22472 URL: https://nbpublish.com/library_read_ article.php?id=22472

6. Официальный сайт МИД Индии. Режим доступа: https://mea.gov.in/

7. Материалы о сотрудничестве Индии и Бутана на сайте посольства Республики Индии в Королевстве Бутане. URL: https://indembthimphu.gov.in/pages.php?id=34 (дата обращения: 22.05.2019).

8. More than the Doklam issue, Bhutan worried about hydropower deficits // The Indian Express, 30.07.2017.URL: https://indianexpress.com/article/opinion/columns/more-than-the-doklam-issue-bhutan-worried-abouthydropower-deficits-4768598/ (дата обращения: 08.05.2019).

9. Beth Walker, India Bhutan hydropower cooperation fraying at the edges // Thethirdpole.net, 2016. - URL: https:// www.thethirdpole.net/en/2016/10/04/india-bhutan-hydropower-cooperation-fraying-at-the-edges/ (дата обращения: 17.05.2019).

10. Amit Ranjan, India-Bhutan Hydropower Projects: Cooperation and Concerns // Institute of South Asian Studies, National University of Singapore, 2018.- URL: https://www.isas.nus.edu.sg/wp-content/uploads/2018/10/ Working-Paper-No.-309-India-Bhutan-Hydropower-Projects.pdf (дата обращения: 15.05.2019).

11. India-Bhutan sign Rs 4,500 crore Mangdechhu Hydro project's power tariff protocol // The Economic Times, 26.04.2019.- URL: https://economictimes.indiatimes.com/industry/energy/power/india-bhutan-sign-rs-4500crore-mangdechhu-hydro-projects-power-tariff-protocol/articleshow/69053103.cms (дата обращения: 08.05.2019).

12. Hydropower debt, delays biggest challenge in ties with India, say Bhutan officials // The Hindu, 06.09.2017.- URL: https://www.thehindu.com/news/national/hydropower-debt-delays-biggest-challenge-in-ties-with-india-saybhutan-officials/article19630701.ece (дата обращения: 08.05.2019).

13. India and Bhutan: Cross-Country Power Connectivity // The Diplomat, 30.06.2016.- Режим доступа: https:// thediplomat.com/2016/06/india-and-bhutan-cross-country-power-connectivity/ (дата обращения: 08.05.2019).

14. Bhutan's Hydro basket gets smaller as India becomes power surplus and tariff rates drop // The Bhutanese, 22.07.2017.- Режим доступа: https://thebhutanese.bt/bhutans-hydro-basket-gets-smaller-as-india-becomespower-surplus-and-tariff-rates-drop/ (дата обращения: 08.06.2019). 